\title{
Lesões granulomatosas encontradas em bovinos abatidos para consumo ${ }^{1}$
}

\author{
Bianca Tessele ${ }^{2}$, Tessie Beck Martins ${ }^{2}$, Andréia Vielmo ${ }^{3}$ e Claudio S.L. Barros ${ }^{4 *}$
}

\begin{abstract}
Tessele B., Martins T.B., Vielmo A. \& Barros C.S.L. 2014. [Granulomatous lesions found in cattle slaughtered for meat production.] Lesões granulomatosas encontradas em bovinos abatidos para consumo. Pesquisa Veterinária Brasileira 34(8):763-769. Departamento de Patologia, Universidade Federal de Santa Maria, Camobi, Santa Maria, RS 97105-900, Brazil.E-mail: claudioslbarros@uol.com.br

In order to help professionals of veterinary medicine in recognizing bovine lesions found during meat inspection at slaughterhouses, three granulomatous conditions of cattle were researched and their morphological similarities and differences were assessed. These three granulomatous conditions were actinobacillosis (caused by Actinobacillus lignieresii), actinomycosis (caused by Actinomyces bovis) and staphylococcal mastitis (caused by Staphylococcus aureus). Out of 505 lesions found in cattle slaughtered for human consumption, 40 were one of the three granulomatous conditions: 24 were actinobacillosis, 10 were actinomycosis and six were staphylococcal mastitis. Overall the gross and histological features of these three diseases are quite similar but their location helps give away the etiology. A. lignieresii affected soft tissues, mainly those of tongue and lymph nodes of the head region; $A$. bovis affected bone tissue mainly that of the mandible; and $S$. aureus main targeted tissue was the mammary gland. Histologically the granuloma resulting from the infection with either one of these three causal agents contained centrally located amorphous, eosinophilic, club like structures surrounded by viable and dead neutrophils. These were surrounded by a mantle of epithelioid macrophages and occasional multinucleated giant cells. These macrophage mantles were irregularly infiltrate by lymphocytes and plasma cells which tended to accumulate to the periphery of the lesion which, in turn, was fenced by a fibrous connective capsule. Given the employment of adequate techniques the causative the agent could be seen within or surrounding the clublike structures in each the three types of granulomatous lesions. In the case of staphylococcal mastitis, intralesional cocci were observed both in HE and Gram stained preparations, in the latter as gram-positive cocci. The agent in actinobacillosis (gram-negative bacilli) and actinomycosis (gram-positive bacilli) could only be observed in Gram stained preparations. The differential diagnosis for these lesions is included in the discussion of this paper.
\end{abstract}

INDEX TERMS: Cattle, abattoir lesions, granulomatous inflammation, granulomas, Actinobacillus lignieresii, Actinomyces bovis, Staphylococcus aureus.

\footnotetext{
${ }^{1}$ Recebido em 31 de julho de 2014.

Aceito para publicação em 20 de agosto de 2014.

Parte da Tese de Doutorado do primeiro autor.

${ }^{2}$ Programa de Pós-Graduação em Medicina Veterinária, área de concentração em Patologia Veterinária, Centro de Ciências Rurais (CCR), Universidade Federal de Santa Maria (UFSM), Avenida Roraima 1000, Camobi, Santa Maria, RS 97105- 900, Brasil.

${ }^{3}$ Bolsista do PROBIC, FAPERGS, no Departamento de Patologia da UFSM, Santa Maria, RS.

${ }^{4}$ Departamento de Patologia, LPV- UFSM, Avenida Roraima 1000, Santa Maria, RS, 97105- 900, Brasil. Pesquisador 1A do CNPq. *Autor para correspondência: claudioslbarros@uol.com.br
}

RESUMO.- Com o objetivo auxiliar profissionais médico-veterinários no reconhecimento das lesões de bovinos encontradas na linha de inspeção de carnes em matadouros frigoríficos, três condições granulomatosas de bovinos foram pesquisadas e suas semelhanças e diferenças avaliadas. Essas três condições granulomatosas foram actinobacilose (causada por Actinobacillus lignieresii), actinomicose (causada por Actinomyces bovis) e mastite estafilocócica (causada por Staphylococcus aureus). Em 505 lesões encontradas em bovinos abatidos para consumo humano, 40 eram uma dessas três lesões granulomatosas: 24 eram 
actinobacilose, 10 eram actinomicose e seis eram mastite estafilocócica. De um modo geral, os aspectos macro e microscópicos dessas três lesões eram bastante semelhantes, mas suas localizações ajudavam a presumir sua etiologia. A. lignieresii afetou tecidos moles, principalmente língua e linfonodos da cabeça; $A$. bovis afetou o tecido ósseo, principalmente o da mandíbula; e $S$. aureus teve a glândula mamária como o tecido alvo. Histologicamente, os granulomas resultantes da infecção por qualquer um desses três agentes continham uma estrutura amorfa, eosinofílica, com clavas irradiadas, localizada centralmente; essa estrutura era rodeada por neutrófilos íntegros e degenerados, que, por sua vez, eram cercados por um manto de macrófagos epitelioides e ocasionais células gigantes multinucleadas. Esses mantos de macrófagos eram irregularmente infiltrados por linfócitos e plasmócitos que tendiam a se acumular na periferia da lesão, que era cercada por uma cápsula de tecido conjuntivo. Dependendo da aplicação do método de coloração adequado, o agente etiológico podia ser visto em cada um dos três tipos de lesão granulomatosa. No caso da mastite estafilocócica, cocos intralesionais foram observados tanto nas colorações por HE como nas de Gram, nessa última como cocos gram-positivos. 0 agente da actinobacilose (bacilos gram-negativos) e da actinomicose (bacilos gram-positivos) pôde ser observado somente nas colorações de Gram. Os diagnósticos diferenciais para essas três condições são discutidos.

TERMOS DE INDEXAÇÃO: Bovinos, lesões de matadouro, inflamação granulomatosa, granulomas, Actinobacillus lignieresii, Actinomyces bovis, Staphylococcus aureus.

\section{INTRODUÇÃO}

Actinobacilose, actinomicose e mastite estafilocócica são doenças bacterianas infecciosas observadas comumente em bovinos destinados ao abate. Embora as lesões provocadas por esses agentes tenham localizações bem definidas, microscopicamente são virtualmente idênticas, caracterizadas por reação granulomatosa típica ao redor de estruturas conhecidas como fenômeno de Slendore-Hoeppli (Till \& Palmer 1960, Schlafer \& Miller 2007, Thompson 2007). Em 2012, apenas no estado do Rio Grande do Sul, foram documentadas pelo serviço de inspeção federal (SIF), mais de 12 mil condenações por actinobacilose e mais de 700 por actinomicose (Brasil 2012). Não há dados disponíveis em relação à mastite estafilocócica, pois no quadro de condenações do SIF as mastites não são classificadas separadamente por etiologia.

A actinobacilose é caracterizada por inflamação em tecidos moles, comumente língua e linfonodos da cabeça e pescoço (Gelberg 2012). Apresentações mais raras da doença em bovinos ocorrem na cavidade nasal, nas glândulas salivares, nos pulmões, na pele, no tecido subcutâneo da cabeça e pescoço, no esôfago, estômagos e omento (Till \& Palmer 1960, Mortimer 1962, Campbell et al. 1975, Sheikh-Omar 1980, Rebhun et al. 1988, Radostits et al. 2007). Actinobacilose generalizada foi descrita envolvendo coração, fígado, rins e linfonodos cervicais (Franco 1970). A doença é causada por Actinobacillus lignieresii, cocobacilo gram-negativo, comensal do trato digestório de bovinos. Alimentos fibrosos ou grosseiros e erupções ou abrasões dentárias possibilitam a invasão do agente e seu acesso aos linfonodos regionais ou outros órgãos por via linfática ou sanguínea. A infecção pode ocorrer, também, por via aerógena, ocasionando a forma pulmonar da doença (Méndez \& Riet-Correa 2007), ou de modo iatrogênico (Rebhun et al. 1988).

Actinomicose em bovinos é uma osteomielite e, embora já tenha sido descrita em diferentes regiões anatômicas, como pênis e traqueia (Basile \& Diniz 1979, Bertonce \& Rebhun 1984), a lesão clássica é localizada na mandíbula e, mais raramente, na maxila (Wilson 2005, Thompson 2007, Tessele et al. 2014). É causada por Actinomyces bovis, bacilo filamentoso gram-positivo, comensal da cavidade oral, porém lesões da mucosa oral por corpos estranhos ou outros agentes proporcionam a invasão dos tecidos pelo micro-organismo. A osteomielite desenvolve-se por extensão direta por infecção na gengiva ou periodontal ou através dos vasos linfáticos (Thompson 2007).

Staphylococcus aureus é reconhecido como o patógeno frequentemente isolado em casos de mastite em muitas espécies, especialmente em porcas (Brown et al. 2007). Está relacionado entre os micro-organismos mais contagiosos e responsável por grandes prejuízos à pecuária leiteira (Fagundes \& Oliveira 2004; Ferreira et al. 2006). S. aureus é um coco gram-positivo de aproximadamente $1 \mu \mathrm{m}$ de diâmetro, coagulase-positivo, que tende a formar agrupamentos em arranjos semelhantes a cachos de uva (Quinn et al. 2005). As cepas de $S$. aureus isoladas da glândula mamária bovina variam de não patogênicas a altamente patogênicas. A forma mais grave de mastite estafilocócica é a forma gangrenosa, normalmente observada logo após o parto. $\mathrm{Na}$ mastite estafilocócica crônica há formação de abscessos. Ocasionalmente nessa forma, os mico-organismos apresentam-se rodeados por rosetas de material claviriforme (reação de Splendore-Hoeppli), nesses casos o termo botriomicose é aplicado às lesões (Foster 2013). Staphylococcus spp. produzem vários fatores de virulência que contribuem para que a bactéria rompa as defesas fagocíticas do hospedeiro, favorecendo a instalação e manutenção do micro-organismo nos tecidos (Coelho et al. 2011). Esses fatores de virulência incluem os polissacarídeos capsulares que bloqueiam a fagocitose por neutrófilos e macrófagos, levando à cronificação da inflamação com fibrose, que é uma manifestação comum da mastite provocada por $S$. $a u$ reus (Zachary 2012).

O objetivo deste trabalho é fazer uma descrição macro e microscópica das principais doenças granulomatosas bacterianas observadas em bovinos destinados a abatedouros-frigoríficos, avaliando meios de diagnóstico diferencial, com a finalidade de auxiliar profissionais da inspeção e médicos veterinários patologistas no seu reconhecimento.

\section{MATERIAL E MÉTODOS}

De janeiro de 2011 a julho de 2014 amostras de lesões de bovinos destinados ao abate foram recebidas no Laboratório de Patologia Veterinária (LPV) da Universidade Federal de Santa Maria (UFSM) e visitas periódicas a diferentes abatedouros-frigoríficos foram realizadas para colher amostras das lesões observadas na linha 
de abate. 0 material foi fotografo e fragmentos dos tecidos foram colhidos, fixados em formol a $10 \%$, clivados e processados para exame histológico de rotina. Os casos de lesões granulomatosas foram selecionados e, dessas lesões, adicionalmente à coloração por hematoxilina eosina (HE), várias secções foram coradas pela técnica de Gram MacCallum-Goodpasture.

\section{RESULTADOS}

Durante 43 meses foram colhidas, em matadouros-frigoríficos, 505 amostras de lesões em tecidos de bovinos de diferentes regiões do Brasil. Dessas 505 amostras, 24 foram de actinobacilose (5\%), 10 de actinomicose (2\%) e seis de mastite estafilocócica (1\%). Dos 24 casos de actinobacilose, oito afetaram apenas a língua; sete apenas os linfonodos retrofaríngeos; três as bochechas; um os pulmões; um o fígado; um a musculatura esquelética da região cervical; um afetou concomitantemente a língua e os linfonodos retrofaríngeos; um o fígado e os pulmões concomitantemente; e, em um caso, foram afetados vários locais da cabeça incluindo língua, linfonodos retrofaríngeos, músculos mastigatórios e lábios.

Os tecidos afetados por Actinobacillus lignieresii apresentaram-se aumentados de volume com múltiplos nódulos de dimensões variadas e firmes, rodeados por tecido brancacento. Os nódulos eram constituídos por tecido marrom claro, macio e continham pequenos pontos amarelos que, quando pressionados, deixavam sobressair gotas de líquido viscoso amarelo. No centro dessas áreas, principalmente em lesões de linfonodos, observava-se pus amarelo espesso, brilhoso, com alta coesão (não se dissociava) e baixa adesividade (desprendia-se facilmente da parede do
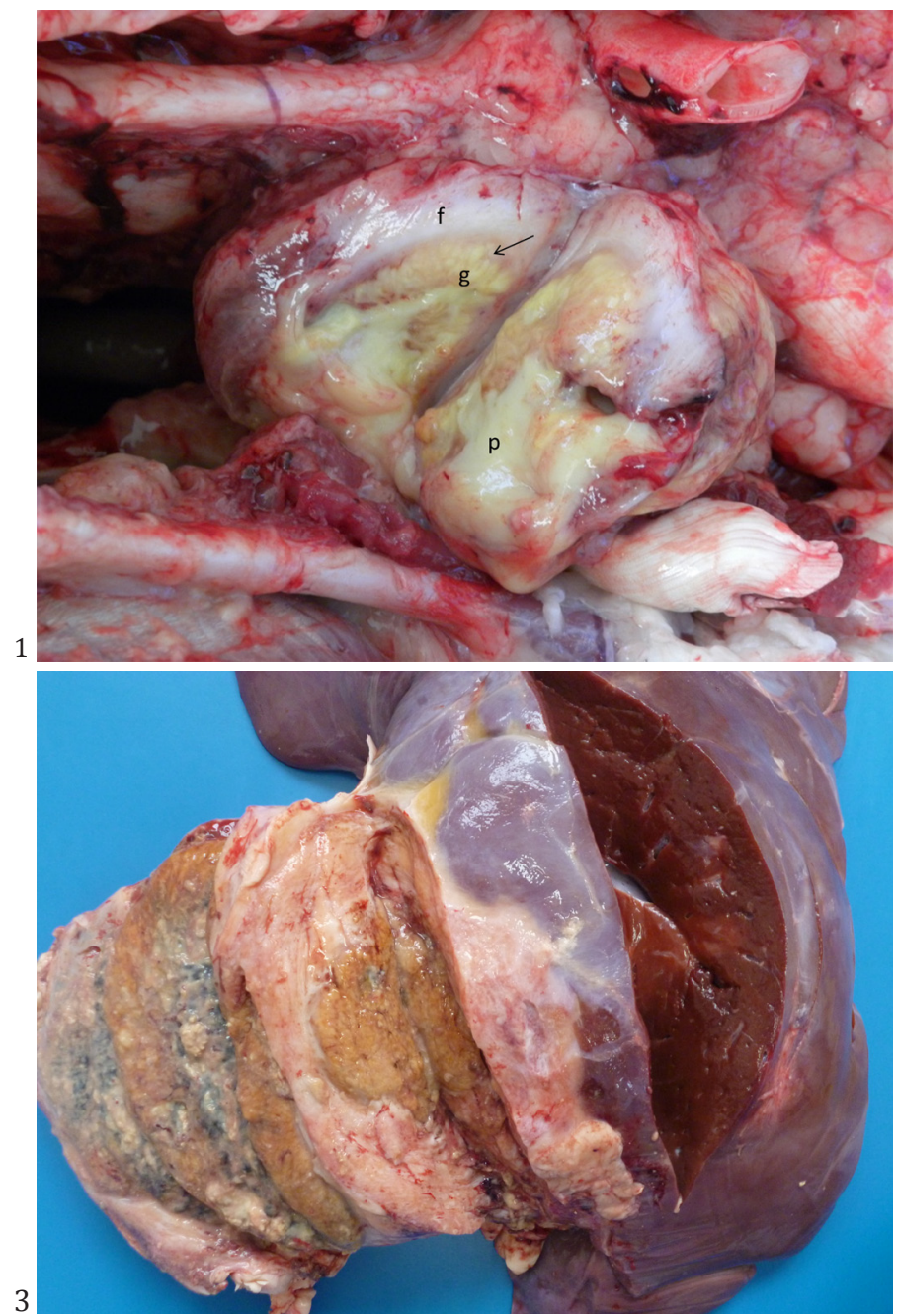

Fig.1. Lesão de actinobacilose no linfonodo retrofaríngeo de um bovino. Os piogranulomas encontram-se rodeados por tecido fibroso brancacento (f). Os nódulos piogranulomatosos são constituídos por tecido marrom claro, macio (g) e contêm pequenos pontos amarelos (seta) que, quando pressionados deixam fluir pequenas gotas de líquido amarelo viscoso. No centro dessas áreas observa-se pus amarelo espesso (p), brilhoso, com alta coesão e baixa adesividade.

Fig.3. Lesão de actinobacilose fígado de um bovino. Observe o tecido necrótico enegrecido.
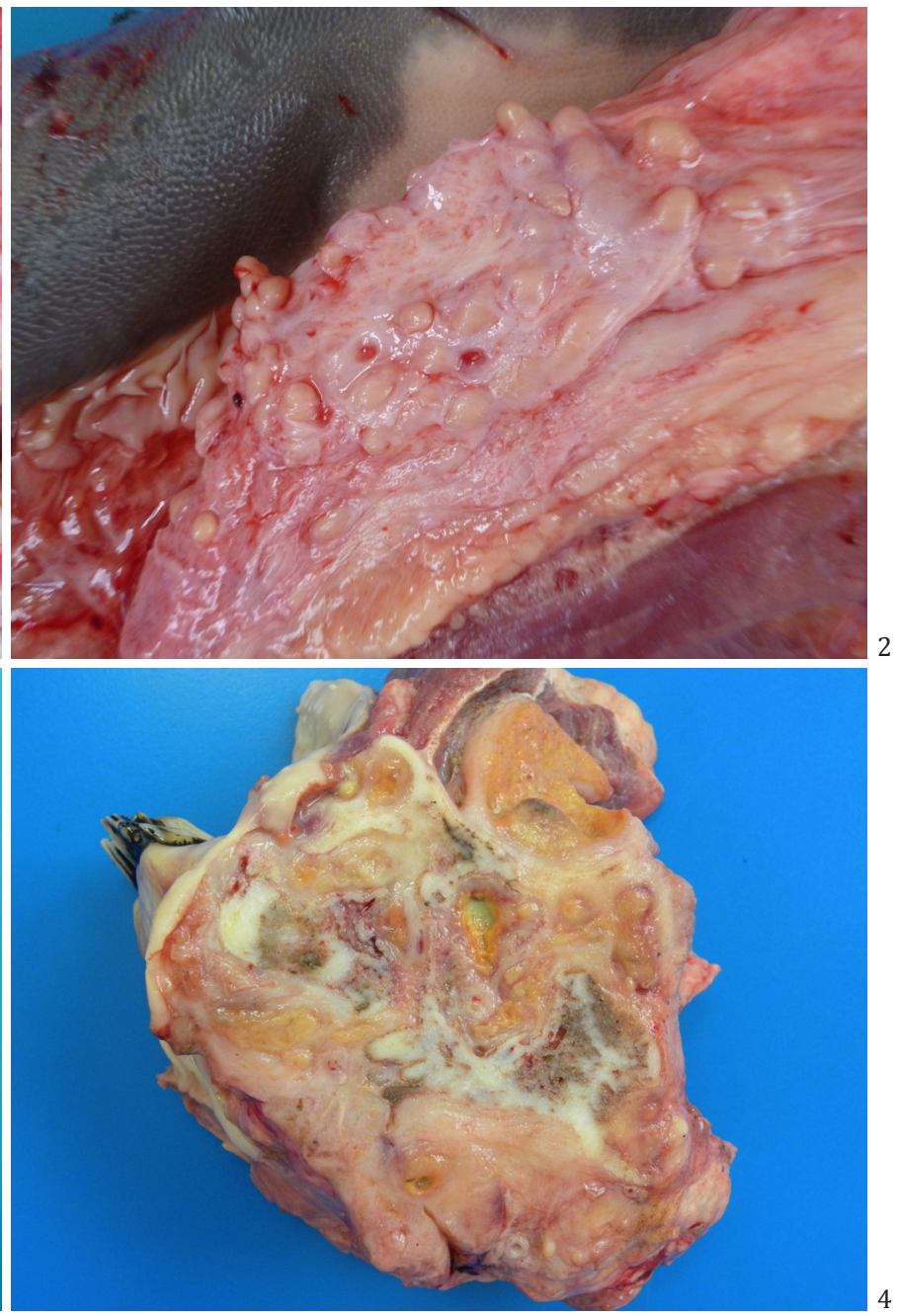

Fig.2. Lesão de actinobacilose na língua de um bovino. Múltiplos nódulos firmes são observados. Ao corte, esses nódulos apresentavam o mesmo aspecto que a lesão descrita na Figura 1, mas sem a presença abundante, no centro da lesão, de pus amarelo espesso, com alta coesão e baixa adesividade.

Fig.4. Actinomicose na mandíbula de um bovino. Múltiplos piogranulomas circundados por septos de tecido ósseo. A proliferação óssea associada à osteíte piogranulomatosa causa o aumento de volume da mandíbula. 

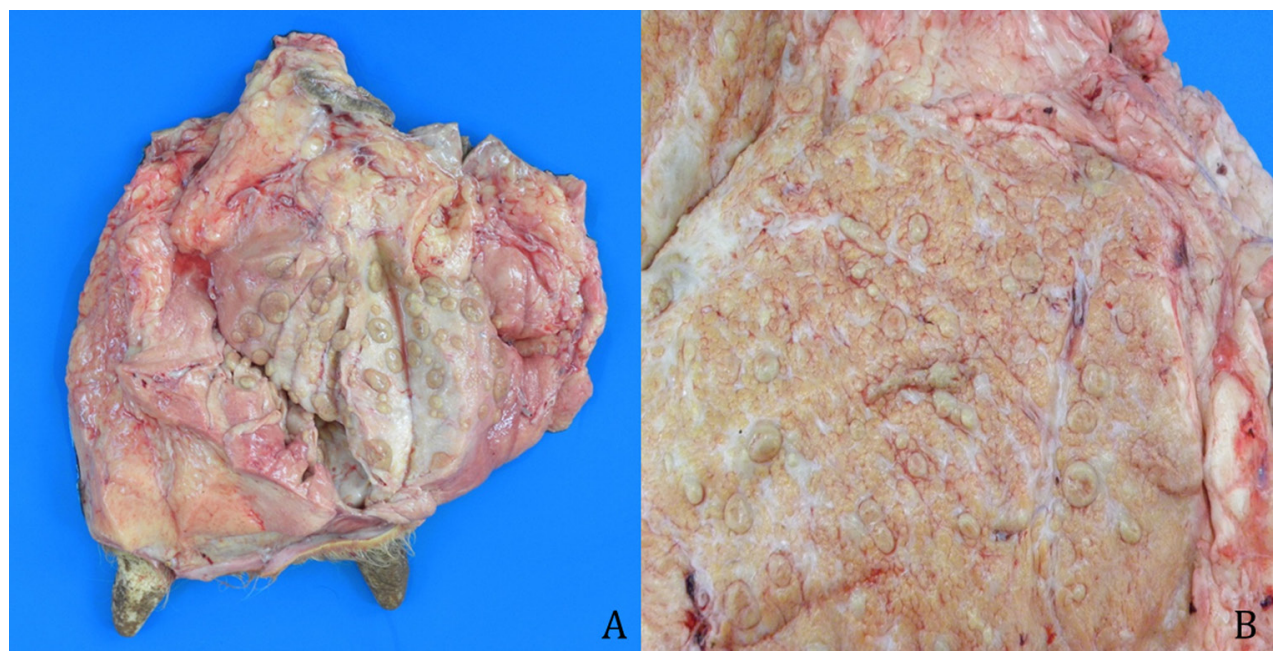

Fig.5. Mastite estafilocócica em bovino. (A) A glândula mamária esta aumentada de volume e firme. Observam-se múltiplos nódulos marrons claros de diferentes tamanhos circundadas por bandas de tecido fibroso brancacento. No centro desses nódulos podem ser observados pequenos pontos de material purulento, semelhantes aos encontrados nos casos de actinobacilose e actinomicose. (B) Maior aproximação mostrando os nódulos piogranulomatosos que se salientam do tecido mamário.

tecido inflamatório) (Fig.1). As lesões na língua eram tipicamente constituídas por múltiplos nódulos firmes (Fig.2) que ao corte apresentavam o mesmo aspecto que as lesões de outros locais, mas sem a presença abundante de pus no centro da lesão. Em um dos casos de actinobacilose hepática (Fig.3), em meio ao tecido inflamatório observava-se material necrótico enegrecido. Nos dois casos em que os pulmões foram afetados, os nódulos estavam restritos a apenas um dos lobos pulmonares.

Dos 10 casos de actinomicose, oito apresentaram a forma clássica da doença, com a lesão restrita ao osso mandibular, e dois casos tiveram uma apresentação atípica, em que a lesão envolvia o osso maxilar com invasão e obstrução quase completa da cavidade nasal. Esses dois casos de lesões atípicas foram relatados separadamente (Tessele et al. 2014). Em todos os casos, as lesões macroscópicas foram caracterizadas por osteomielite proliferativa unilateral com áreas piogranulomatosas circundadas por septos de tecido ósseo (Fig.4). Muitos nódulos estavam necróticos evidenciados por áreas verdes escuras. Frequentemente, observaram-se fístulas, que se se estendiam até os tecidos moles e drenavam fluido espesso branco-amarelado e com grânulos amarelos.

Nos casos de mastite estafilocócica a glândula mamária estava aumentada de volume e firme devido à múltiplos nódulos amarelos de diferentes tamanhos circundados por bandas de tecido fibroso brancacento (Fig. 5). No centro desses nódulos foram observados pequenos pontos de material purulento.

Microscopicamente, as lesões dos casos de actinobacilose, actinomicose e mastite estafilocócica eram muito semelhantes. Foram caracterizadas por múltiplos piogranulomas constituídos por uma massa de estruturas eosinofílicas em forma de clavas dispostas radialmente (fenômeno de Splendore-Hoeppli). As clavas eram cercadas por quantidade variável de neutrófilos íntegros ou degenerados que, por sua vez, eram rodeados por macrófagos epitelioides, com ocasionais células gigantes multinucleadas (Fig.6). Ocasionalmente, fragmentos das clavas eosinofílicas eram observados no citoplasma de células gigantes. Infiltrado de linfócitos e plasmócitos ocorriam perifericamente associado ao tecido conjuntivo neoformado. Mineralização nas áreas centrais dos piogranulomas foi um achado frequente. Nos casos de mastite estafilocócica,

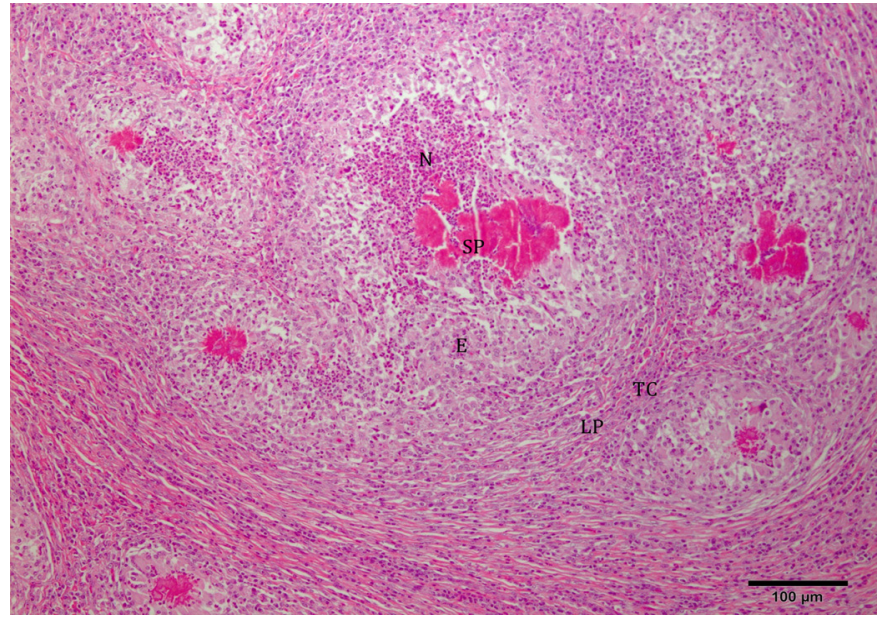

Fig.6. Aspecto histológico da lesão de actinobacilose no músculo da região cervical de um bovino. Podem ser observados múltiplos piogranulomas (oito nesta ilustração) constituídos por estruturas eosinofílicas em forma de clavas, dispostas radialmente. Essas estruturas são conhecidas como fenômeno de Splendore Hoepli (SP). As clavas são cercadas por quantidade variável de neutrófilos $(\mathrm{N})$ que são rodeados por macrófagos epitelioides (E). Infiltrado de linfócitos e plasmócitos (LP) ocorria perifericamente associado ao tecido conjuntivo (TC) neoformado. HE, obj.20x.

os cocos bacterianos eram facilmente visíveis no centro dos piogranulomas pela coloração de HE (Fig.7).

Pela técnica de Gram pôde-se evidenciar a morfologia bacteriana no centro dos piogranulomas. Todos os casos de actinobacilose foram caracterizados pela presença de pequena quantidade de cocobacilos gram-negativos (Fig. 8). Nos casos de actinomicose evidenciou-se grande quantidade de bacilos filamentosos gram-positivos (Fig.9). Nos casos de mastite estafilocócica os micro-organismos gram-positivos observados associados às lesões eram agrupamentos de cocos (Fig.10).

\section{DISCUSSÃO}

As lesões histológicas de actinobacilose, actinomicose e mastite estafilocócica são muito semelhantes, praticamente impossíveis de diferenciar pela coloração por HE, a não ser 


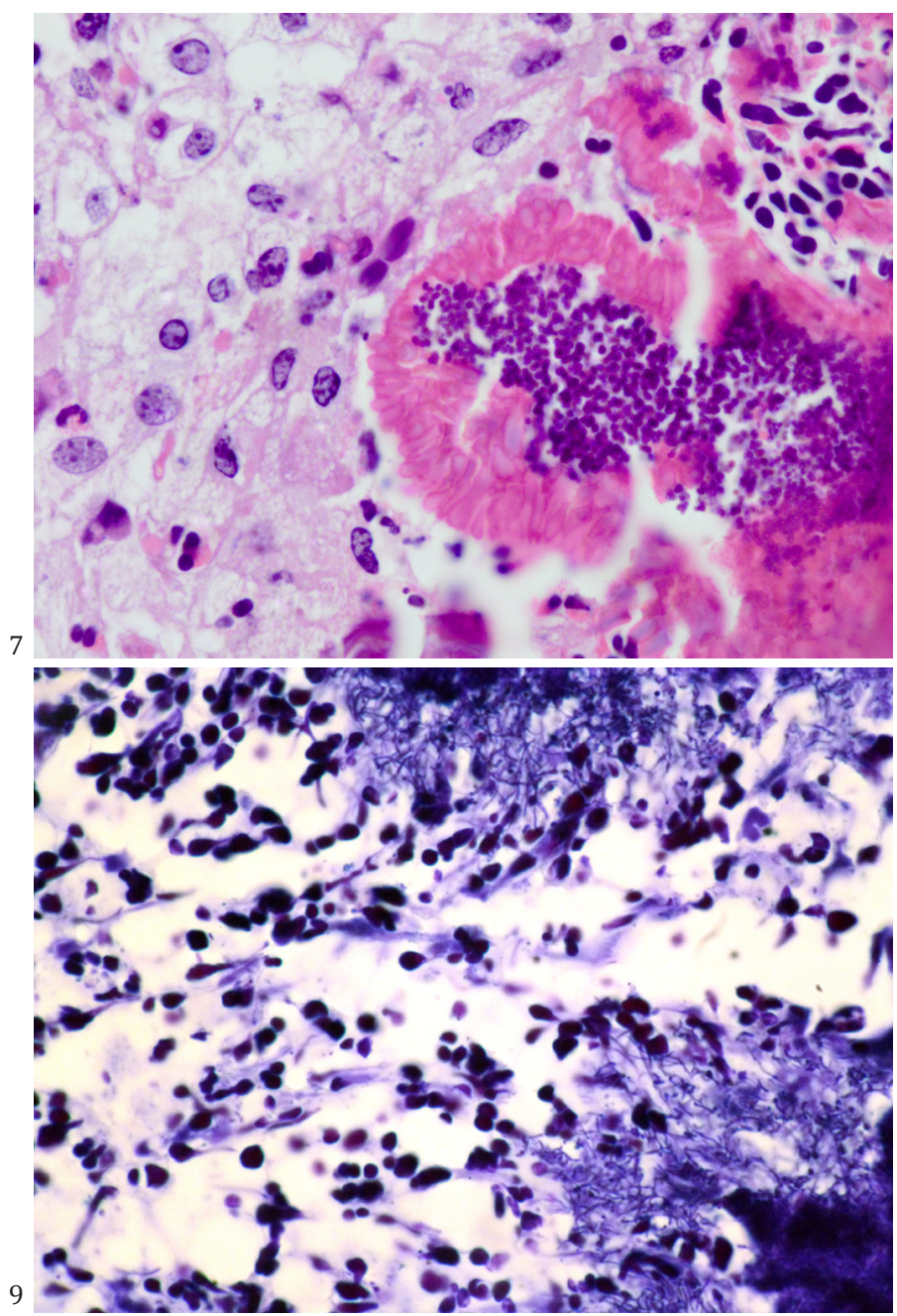

Fig.7. Aspecto histológico da mastite estafilocócica em bovinos. Bactérias cocoides podem ser observadas em meio à estrutura eosinofílica em forma de clava (à direita). Á esquerda observam-se macrófagos epitelioides. HE, obj.40x.

Fig.9. Aspecto histológico da actinomicose em bovino. Aglomerados de bacilos filamentosos gram-positivos (corados em azul) podem ser observados nos cantos superior e inferior direitos da figura. MacCallum-Goodpasture, obj.100x (imersão).

pelo conhecimento da localização anatômica de cada condição e, no caso da mastite, pela fácil visualização dos organismos cocoides no centro dos piogranulomas (Schlafer \& Miller 2007). A actinobacilose é uma doença que afeta exclusivamente os tecidos moles, preferencialmente língua e linfonodos regionais (Wilson 2005), como se pôde perceber em nosso estudo, em que, dos 24 casos de actinobacilose, 16 estavam localizados nesses sítios anatômicos, perfazendo $67 \%$ de todos os casos. Já a actinomicose é caracterizada por causar osteomielite, principalmente no osso mandibular (Wilson 2005, Thompson 2007) e a mastite estafilocócica por afetar exclusivamente a glândula mamária, uma condição conhecida como botriomicose (Foster 2012).

Alguns autores afirmam que a diferenciação entre actinomicose e actinobacilose pode ser feita pela morfologia das colônias e da reação de Splendore-Hoeppli. Na actinomicose, as primeiras seriam maiores e a última apresen-
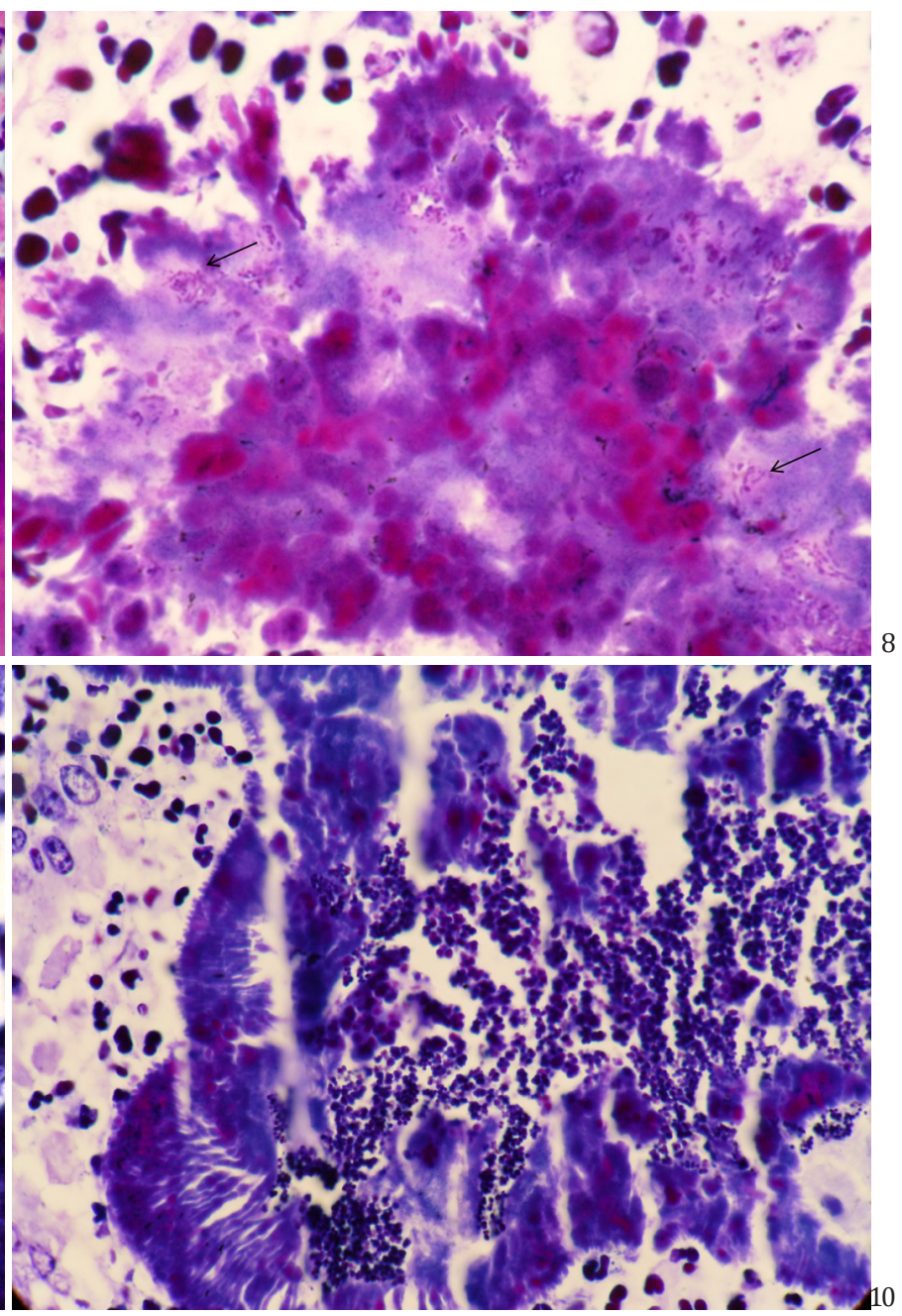

Fig.8. Aspecto histológico da actinobacilose em bovino. As lesões estão associadas à pequena quantidade de cocobacilos gram-negativos (corados em vermelho [setas]). MacCallum-Goodpasture, obj.100x (imersão).

Fig.10. Aspecto histológico da mastite estafilocócica em bovino. Micro-organismos gram-positivos cocoides podem ser observados em meio à lesão. MacCallum-Goodpasture, obj.100x (imersão).

taria clavas menores e menos definidas, geralmente localizadas na periferia das colônias (Till \& Palmer 1960). A morfologia dos micro-organismos em nossos casos pôde ser percebida após a coloração pela técnica de Gram, que evidenciou agrupamentos formados por numerosos bacilos filamentosos gram-positivos nos casos de actinomicose, diferentemente dos bacilos gram-negativos da actinobacilose, que eram pequenos e pouco numerosos em todos os casos. A distribuição das clavas eosinofílicas perifericamente foi observada na maioria das reações de Splendore-Hoeppli dos casos de actinomicose. Isoladamente, a morfologia dessa estrutura não parece ser uma característica confiável para definir o diagnóstico, uma vez que em alguns casos de actinobacilose e de mastite estafilocócica foi evidenciada distribuição semelhante.

Houve grande variação na quantidade de tecido conjuntivo fibroso nos diferentes casos desse estudo, porém isso 
não parece estar relacionado mais com uma ou outra condição, uma vez que a quantidade de tecido fibroso presente depende da duração do processo inflamatório e do edema (Gelberg 2012). É essa extensa proliferação de tecido conjuntivo fibroso que faz com que a língua de bovinos afetados por actinobacilose fique firme ou dura, muitas vezes contraída e imóvel, dificultando a apreensão de alimentos, motivo da denominação coloquial "língua de pau" para a condição (Radostits et al. 2007).

Os pequenos grânulos amarelos observados macroscopicamente nos tecidos afetados são denominados coloquialmente de "grãos de enxofre" devido à sua cor (Brewer 1956) e foram especialmente visíveis nos casos de actinobacilose e actinomicose. Esses grânulos representam as colônias bacterianas e, microscopicamente, correspondem à reação de Splendore-Hoeppli (Miller \& Haddad 1998). Esse fenômeno, que corresponde a agregados proteináceos eosinofílicos de imunoglobulinas, embora seja comum nos casos de actinobacilose, actinomicose e mastite estafilocócica, não é exclusivo dessas condições. Exemplos menos comuns de lesões microscópicas similares incluem infecção por Nocardia, vários agentes associados com micetomas (Brown et al. 2007) e granulomas produzidos por Mannheimia granulomatis (Ladeira 2007). Estruturas semelhantes à reação de Splendore-Hoeppli foram descritas em piogranulomas parasitários por Oesophagostomum em bovinos (Tessele et al. 2013).

Os casos de actinobacilose e actinomicose com localizações atípicas que alguns bovinos desse estudo apresentaram, como pulmão, musculatura esquelética, lábio e fígado e osso maxilar, podem dificultar o diagnóstico macroscópico por profissionais médicos veterinários durante a inspeção de carnes ou durante o exame clínico ou de necropsia. Algumas características são importantes e devem ser cuidadosamente avaliadas. Uma delas é a presença de pus amarelo espesso, brilhoso, com alta coesão e baixa adesividade frequentemente associado aos nódulos de actinobacilose, principalmente aos dos linfonodos (Jones et al. 1997). Esse material é mais brilhante do que o material caseoso observado em casos dos tubérculos. Nessa última condição, o material caseoso revela uma consistência arenosa quando a lesão é cortada com a faca. Essa consistência arenosa é dada pela mineralização da necrose central nos granulomas de tuberculose, aspecto que não ocorre na actinobacilose. Além disso, os nódulos na actinobacilose tendem a sobressair ao tecido adjacente, diferentemente das lesões tuberculosas, que são planas, quando não calcificadas. (Wilson 2005). Em nossos casos de actinobacilose hepática, os pequenos pontos de pus, que foram observados na periferia da lesão, auxiliaram no diagnóstico macroscópico dessa condição. Já nos dois casos de actinomicose no osso maxilar, devido à grande extensão das lesões e às características invasivas, o carcinoma de células escamosas intranasal foi incluído no diagnóstico diferencial (Wilson \& Dungworth 2002, Tessele et al. 2014).

\section{CONCLUSÕES}

Concluindo, lesões com os aspectos macro e microscópicos descritos neste estudo devem ser consideradas da seguinte maneira: actinobacilose se foram encontradas nos tecidos moles, com exceção da mama, como actinomicose se forem encontradas no tecido ósseo e como mastite estafilocócica (botriomicose) se forme encontradas na glândula mamária.

Em colorações de Gram no material histológico, esse diagnóstico inicial pode ser confirmado: na actinobacilose serão observados cocobacilos gram-negativos, na actinomicose bacilos filamentosos gram-positivos e na mastite estafilocócica cocos gram-positivos.

\section{REFERÊNCIAS}

Brasil 2012. Destino de matérias-primas e produtos por UF. Ministério da Agricultura, Pecuária e Abastecimento (MAPA), Brasília. 11p.

Brown C.C., Baker D.C. \& Barker I.K. 2007. Alimentary system, p.1-296. In: Maxie M.G. (Ed.), Jubb, Kennedy, and Palmer's Pathology of Domestic Animals. Vol.2 and 3. $5^{\text {th }}$ ed. Elsevier Saunders, Philadelphia.

Campbell S.G., Whitlock T.R.H., Timoney J.F. \& Underwood A.M. 1975. An unusual epizootic of actinobacillosis in dairy heifers. J. Am. Vet. Med. Assoc. 166:604-606.

Coelho S.M.O., Pereira I.A., Soares L.C., Pribul B.R. \& Souza M.M.S. 2011. Profile of virulence factors of Staphylococcus aureus isolated from subclinical bovine mastitis in the state of Rio de Janeiro, Brazil. J. Dairy Sci. 94:3305-3310.

Fagundes H. \& Oliveira C.A.F 2004. Infecções intramamárias causadas por Staphylococcus aureus e suas implicações em saúde pública. Ciência Rural 34:1315-1320.

Ferreira L.M., Nader Filho A., Oliveira E., Zafalon L.F. \& Souza V. 2006. Variabilidades fenotípica e genotípica de estirpes de Staphylococcus aureus isoladas em casos de mastite subclínica bovina. Ciência Rural 36:1228-1234.

Foster R.A. 2012. Female reproductive system and mammary gland, p.10858-1126. In: Zachary J.F. \& McGavin M.D. (Eds), Pathologic Basis of Veterinary Disease. $5^{\text {th }}$ ed. Elsevier, St Louis.

Franco D.A. 1970. Generalized actinobacillosis in a Holstein cow (postmortem lesions). Vet. Med. Small Anim. Clin. 65:562.

Gelberg H.B. 2012. Alimentary System and peritoneum, omentum, mesentery, and peritoneal cavity, p.322-404. In: Zachary J.F. \& McGavin M.D. (Eds), Pathologic Basis of Veterinary Disease. $5^{\text {th }}$ ed. Elsevier, St Louis.

Jones T.C., Hunt R.D. \& King N.W. 1997. Actinobacillus lignieresii, p.456457. In: Ibid. (Eds), Veterinary Pathology. $6^{\text {th }}$ ed. Williams and Wilkin, Baltimore.

Ladeira S.R.L. 2007. Lechiguana, p. 325-330. In: Riet-Correa F., Schild A.L., Lemos R.A.A. \& Borges J.R.J. (Eds), Doenças de Ruminantes e Eqüídeos. Vol. 1. Pallotti, Santa Maria.

Méndez M.C. \& Riet-Correa F. 2007. Actinobacilose, p. 208-212. In: Riet-Correa F., Schild A.L., Lemos R.A.A. \& Borges J.R.J. (Eds), Doenças de Ruminantes e Eqüídeos. Vol.1. Pallotti, Santa Maria.

Mortimer P.H. 1962. An extrathoracic oesophageal lesion, later attributed to actinobacillosis, causing unusual symptoms in a dairy cow. Vet. Rec. 74:392-394.

Quinn P.J., Markey B.K., Carter M.E., Donnelly W.J. \& Leonard F.C. 2005. Gênero Staphylococcus, p.55-60. In: Ibid. (Eds), Microbiologia Veterinária e Doenças Infecciosas. Artmed, Porto Alegre.

Radostits O.M., Gay C.C., Hinchcliff K.W. \& Constable P.D. 2007. Diseases associated with bacteria, p. 1007-1060. In: Ibid. (Eds), Veterinary Medicine: a textbook of the diseases of cattle, horses, sheep, pigs, and goats. Saunders Elsevier, Spain.

Rebhun W.C., King J.M. \& Hillman R.B. 1988. Atypical actinobacillosis granulomas in cattle. Cornell Vet. 78:125-130.

Schlafer D.H. \& Miller R.B. 2007. Female genital system, p.429-564. In: Maxie M.G. (Ed.), Jubb, Kennedy, and Palmer's Pathology of Domestic Animals. Vol.3. $5^{\text {th }}$ ed. Elsevier Saunders, Philadelphia. 
Sheikh-Omar A.R. 1980. Actinobacillosis of the omentum in a cow. Pertanika 3:64-65.

Tessele B., Brum J.S. \& Barros C.S.L. 2013. Lesões parasitárias encontradas em bovinos abatidos para consumo humano. Pesq. Vet. Bras. 33:873889.

Tessele B., Vielmo A., Hammerschmitt M.E. \& Barros C.S.L. 2014. Actinomicose atípica em bovinos. Pesq. Vet. Bras. 34:663-666.

Thompson K. 2007. Bones and joints, p.1-184. In: Maxie M.G. (Ed.), Jubb, Kennedy, and Palmer's Pathology of Domestic Animals. Vol.1. $5^{\text {th }}$ ed. Elsevier Saunders, Philadelphia.
Till D.H. \& Palmer F.P. 1960. A review of actinobacillosis with a study of the causal organism. Vet. Rec. 72:527-534.

Wilson D.W. \& Dungworth D.L. 2002. Tumors of the respiratory tract, p.365-399. In: Meuten D.J. (Ed.), Tumors in Domestic Animals. Iowa State Press, Ames.

Wilson W.G. 2005. Specific diseases, p.112-136. In: Ibid. (Ed.), Wilson's Practical Meat Inspection. $7^{\text {th }}$ ed. Blackwell, Oxford.

Zachary J.F. 2012. Mechanisms of microbial infection, p.147-241. In: Zachary J.F. \& McGavin M.D. (Eds), Pathologic Basis of Veterinary Disease. $5^{\text {th }}$ ed. Elsevier, St Louis. 